\title{
Erratum: Symmetry-based indicators of band topology in the 230 space groups
}

\author{
Hoi Chun Po 1,2 , Ashvin Vishwanath ${ }^{1,2}$ \& Haruki Watanabe ${ }^{3}$
}

Nature Communications 8:50 doi: 10.1038/s41467-017-00133-2; Article published online: 30 Jun 2017

Due to a production error, this Article was originally published with an incorrect title. The title should have been "Symmetry-based indicators of band topology in the 230 space groups", not "Complete theory of symmetry-based indicators of band topology". This has now been corrected in both the PDF and HTML versions of the Article.

Published online: 10 October 2017

\begin{abstract}
cc) Open Access This article is licensed under a Creative Commons Attribution 4.0 International License, which permits use, sharing, adaptation, distribution and reproduction in any medium or format, as long as you give appropriate credit to the original author(s) and the source, provide a link to the Creative Commons license, and indicate if changes were made. The images or other third party material in this article are included in the article's Creative Commons license, unless indicated otherwise in a credit line to the material. If material is not included in the article's Creative Commons license and your intended use is not permitted by statutory regulation or exceeds the permitted use, you will need to obtain permission directly from the copyright holder. To view a copy of this license, visit http://creativecommons.org/licenses/by/4.0/.
\end{abstract}

(C) The Author(s) 2017

\footnotetext{
${ }^{1}$ Department of Physics, University of California, Berkeley, CA 94720, USA. ${ }^{2}$ Department of Physics, Harvard University, Cambridge, MA 02138, USA

${ }^{3}$ Department of Applied Physics, University of Tokyo, Tokyo 113-8656, Japan. Correspondence and requests for materials should be addressed to A.V. (email: avishwanath@g.harvard.edu)
} 